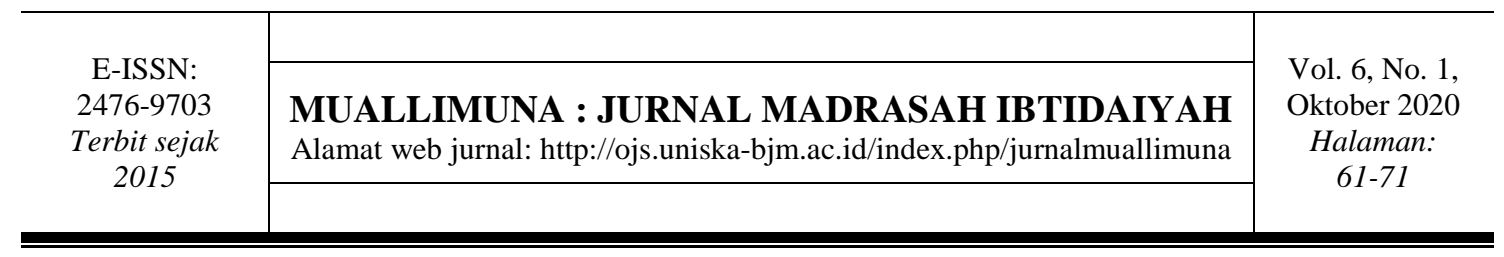

\title{
UPAYA MENUMBUHKAN MINAT BACA SISWA MELALUI BUDAYA LITERASI DI SDIT QURRATA A'YUN KANDANGAN
}

\author{
Shinta Ramadhini ${ }^{1}$, Barsihanor ${ }^{2}$, Muhammad Fahmi Arifin ${ }^{3}$, Abdul Hafiz ${ }^{4}$ \\ ${ }^{1234}$ PGMI, Universitas Islam Kalimantan MAB Banjarmasin, Indonesia \\ ${ }^{1}$ Shintaramadhini54@gmail.com, ${ }^{2}$ barsihanor@uniska-bjm.ac.id \\ ${ }^{3}$ muhammadarifinalbanjari@gmail.com, ${ }^{4}$ abdulhafiz@uniska-bjm.ac.id
}

\begin{abstract}
Abstrak: Penelitian bertujuan untuk mendeskripsikan upaya menumbuhkan minat baca siswa melalui budaya literasi di SDIT Qurrta A'yun Kandangan. Metode penelitian ini peneliti menggunakan pendekatan kualitatif dengan jenis studi kasus dan subjek dalam penelitian ini adalah Kepala Sekolah, Waka Kurikulum Sekolah, Waka Kesiswaan Sekolah, Kepala Perpustakaan, Koordinator Perpustakaan, Guru, Siswa dan Orang tua. Pengumpulan data dilaksanakan melalui observasi, wawancara dan dokumentasi. Teknis analisis yang digunakan penelitia adalah reduksi data, display data, dan penerikan kesimpulan. Peneliti menggunakan trianggulasi Teknik dan trianggulasi sumber untuk memperoleh keabsahan data. Berdasarkan hasil penelitian dapat disimpulkan bahwa upaya menumbuhkan minat baca siswa melalui budaya literasi di SDIT Qurrata A'yun Kandangan dengan upaya melalui kegiatan: 1) Penyediaan buku, 2) Jadwal Literasi, 3) Membuat Mading, 4) Reward, 5) Pojok Baca, dan 6) Perpustakaan Keliling. Faktor pendukung upaya menumbuhkan minat baca siswa melalui budaya literasi di SDIT Qurrata A'yun Kandangan adalah 1) Buku-buku Baru, 2) Motivasi Guru, 3) Fasilitas, 4) Lingkungan, dan 5) Motivasi Orang tua. Faktor penghambat upaya menumbuhkan minat baca siswa melalui budaya literasi di SDIT Qurrata A'yun Kandangan adalah 1) Buku yang tidak diperbaharui, 2) Gadget, 3) Waktu yang tidak mencukupi dan 4) Kurangnya dukungan orang tua.
\end{abstract}

\section{Kata Kunci: Menumbuhkan; Minat Baca; Budaya Literasi}

\section{EFFORTS TO FOSTER STUDENTS' INTEREST THROUGH LITERACY CULTURE AT SDIT QURRATA A'YUN KANDANGAN}

Abstract: This study aims to describe the efforts to foster students 'reading interest through literacy culture at SDIT Qurrta A'yun Kandangan. This research uses a qualitative approach, a case study type with the subject of the Principal, School Curriculum Deputy, School Student Assistant, Head of the Library, Library Coordinator, Teachers, Students and Parents. Data collection was carried out through observation, interviews and documentation. The analysis technique used in this research is data reduction, data display, and conclusion. Researchers used technical triangulation and source triangulation to obtain data validity. Based on the results of the study, it can be concluded that the effort to foster students' reading interest through literacy culture at SDIT Qurrata A'yun Kandangan through the following activities: 1) Provision of books, 2) Schedule of Literacy, 3) Making Wallings, 4) Rewards, 5) Reading Corner and 6) Mobile Library. The supporting factors for the efforts to foster students 'reading interest through literacy culture at SDIT Qurrata A'yun Kandangan are 1) New Books, 2) Teacher Motivation, 3) Facilities, 4) Environment, and 5) Parents' 
Motivation. The inhibiting factors in trying to foster students' interest in reading through literacy culture at SDIT Qurrata A'yun Kandangan are 1) books that are not updated, 2) gadgets, 3) insufficient time and 4) lack of parental support.

\section{Keywords: Cultivating, Reading Interest, Literacy Culture}

\section{PENDAHULUAN}

Pada abad 21 siswa dituntut untuk cerdas, kreatif dan inovatif karena pada berapa tahun kedepan SDM Indonesia diharapkan menjadi SDM unggul dan mampu bersaing secara global. Hal tersebut terwujud apabila siswa mempunyai sumber informasi yang sangat luas. Informasi bisa diperoleh dengan cara membaca (Tarmidzi dan Widya, 2020).

Perpustakaan mempuyai peranan signifikan dan menjadi salah satu faktor tumbuhnya aktivitas gemar membaca dan meningkatkan literasi, juga dalam mengembangkan siswa sehingga dapat belajar secara indepanden (Suherman, 2009). Secara menyeluruh perpustakaan dapat meningkatkan literasi informasi (Yanita, 2014). Dalam upaya menecerdaskan bangsa, perlu dibiasakan budaya literasi gemar membaca melalui pemanfaataan dan pengembangan perpustakaan sebagai sumber informasi (Hartono, 2016).

Membaca merupakan suatu proses memahami isi teks dan suatu pengetahuan oleh seorang pembaca, sebagai peran utama dalam membentuk sebuah makna pada teks. Melalui kegiatan literasi membaca siswa dapat memperoleh banyak pengetahuan (Imran, dkk, 2018). Menurut Musfiroh dan Listyorini membaca dipandang sebagai komponen penting untuk menunjangnya suksesnya suatu sekolah dan siswa membutuhkan kemampuan membaca yang bagus untuk memahami dan memelajari materi yang beragam di kelas (Musfiroh dan Listyorini, 2016).

Membaca juga telah ditegaskan dalam kitab suci Al-Qur'an. Perintah membaca di dalam Al-Qur'an disebutkan dua kali di dalam Surah Al 'Alaq ayat 1 sampai 3 (Mustolehudin, 2018). Pengulangan kata iqra' pada surah ini menunjukan bahwa perintah membaca adalah hal penting bagi kehidupan manusia. Muhammad Quraish Shihab dalam Mustolehudin yang menjelaskan bahwa seseorang yang membaca berarti melakukan aktivitas menelaah, membaca, mendalami, meneliti, dan menghimpun ilmu pengetahuan dan informasi (Mustolehudin, 2018).

Ibnu Katsir berpendapat di dalam surat Al-'Alaq ayat 1-5 merupakan surat yang berbicara tentang permulaan rahmat Allah yang diberikan kepada hamba-Nya, awal dari kenikmatan yang diberikan kepada hamba-Nya dan sebagai tanbih (peringatan) tentang proses awal penciptaan manusia dari 'alaqah. Ayat tersebut juga menjelaskan kemuliaan Allah SWT yang telah mengajarkan manusia sesuatu hal (pengetahuan) yang belum diketahui, sehingga hamba dimuliakan Allah dengan ilmu yang merupakan qudrat-Nya (Abu Fida Al-Hafiz ibn Katsir Al-Dimisqi, 2002).

Kaitannya dengan surat Al-Alaq sangat jelas, bahwa Allah SWT menciptakan manusia sebagai makhluk sempurna yang diberikan potensi yang luar biasa yaitu akal. Allah SWT memerintahkan umat manusia agar menggunakan akal pikiran dengan sebaik-baiknya melalui proses Iqra, sebagaimana yang disebutkan pada awal surat AlAlaq. Ketika ditafsirkan kata Iqra ini memiliki makna yang sangat luas, setidaknya dapat dipahami dalam kandungannya memberikan proses pada dasar pendidikan bagi manusia dengan mengembangkan kemampuan akal yang dimiliki (intelektual) melalui kegiatan membaca (Ahmad Islahud Daroini, 2018). 
Namun sangat disayangkan, menurut beberapa data tentang peringkat literasi yang didapat dari penelitian Program For Internasional Student Assessment (PISA) Rilisan Organization for Economic Co-Operation and Develompent pada tahun 2015 (Danu Damarjati, 2015). 'World's Most Literate Nations' pada Maret 2016, Central Connecticut State University (Hamdani, 2019). Diperkuat dengan hasil penelitian dari United Nations Educational, Scientific and Cultural Organization (Galuh Ayu Puspita, Irwansyah, 2019). serta Indeks Alibaca Provinsi (2019) menunjukan bahwa minat baca masyarakat Indonesia rendah. Menurut Indeks Alibaca Provinsi 24 Provinsi (71\%) masuk kategori rendah (angka indeks 20,01-40,00). Indeks Alibaca tersebut menunjukan bahwa provinsi Kalimantan Selatan juga masuk dalam kategori aktivitas rendah (angka indeks 37,00). (Lukman Solihin dkk, 2019).

Survei tersebut memaparkan bahwa minat baca dan literasi penduduk Indonesia merupakan persoalan yang harus ditangani pemerintah dengan serius. Melalui Peraturan Menteri Pendidikan dan Kebudayaan (Permendikbud) Nomor 23 tahun 2015 tentang Penumbuhan Budi Pekerti, yang salah satu tujuan Permendikbud tersebut berupaya untuk memperkuat budaya literasi siswa (Lukman Solihin dkk, 2019). Dalam rangka meningkatkan literasi masyarakat, sejak 2016 pemerintah melalui Kementrian Pendidikan dan kebudayaan telah merealisasikan program Gerakan Literasi Nasional (GLN) untuk mendorong tumbuhnya budaya minat baca yang dipantau melalui penyelenggaraan Gerakan Literasi Sekolah. (Lukman Solihin dkk, 2019).

Data dari Dinas Pendidikan Kabupaten Hulu Sungai Selatan semua SD yang berada di kabupaten Hulu Sungai Selatan telah diberi tugas untuk menerapkan Literasi yang terrangkum pada kurikulum sekolah. Pelaksanaan di sekolah dilaksanakan sebagiamana yang telah diterapkan oleh pemerintah dan dengan cara masing-masing (Umar Dani, 2019).

Namun, berdasarkan hasil observasi pendahuluan peneliti kebeberapa Sekolah Dasar yang berada di Kabupaten Hulu Sungai Selatan ada sebagian sekolah yang hanya sebatas adanya penerapan Literasi namun penerapannya belum begitu terkelola seperti penetapan jam kunjung literasi kadang tidak terjalankan sepenuhnya dan kondisi ruang perpustakaan yang tidak begitu diperhatikan.

Pada lokasi berbeda di SDIT Qurrata A'yun Kandangan peneliti menemukan sekolah yang memliki beberapa program dan jaminan mutu (Quality Anssurance) dari sekolah salah satu proram sekolah tersebut adalah Budaya Literasi. Berdasarkan hasil observasi peneliti pada saat PPL peneliti melihat sebelum pembelajaran di mulai sekolah melakukan pembiasaan membaca/ menulis/ mendengarkan/ berbicara selama 15-20 menit, peneliti jua melihat ramainya siswa mengunjungi perpustakaan dan Taman baca serta pengadaan madding sekolah tiap bulannya, sekolah juga memberikan reward kepada siswa yang sering membaca dan meminjam buku diperpustakaan. Seperti yang disampaikan Azkia siswi kelas II A mengakatakan siswa yang sering membaca buku di rumah dan di sekolah akan diberi hadiah dari sekolah (Shara Azkia, 2019). Sebagaiman juga yang diungkapkan Anisa Pustakawan sekolah, adanya pembagian jadwal setiap kelas untuk berkunjung ke perpustakaan dan siswa yang sering membaca dan meminjam buku akan diberi reward (Anisa oktaviani, 2019). Selain itu sekolah juga mempunyai fasilitas yang mendukung seperti adanya Perpustakaan, Pojok Baca di dalam kelas dan Taman Baca di Lingkungan Sekolah.

Berdasarkan hasil wawancara dengan Waka Kurikulum SDIT Qurrata A'yun Kandangan kegiatan literasi diterapkan di dalam kegiatan pembelajaran khasnya itu Terpadu T nya itu Telaah, E eksplorasi, R rumuskan, $\mathrm{P}$ presentasikan, A aplikasikan, D 
duniawi dan $U$ yaitu ukhrawi, selain itu di dalam buku penghubung pada saat di rumah siswa juga diminta untuk wajib membaca. Tujuan dari sekolah sendiri dengan adanya penerapan Literasi tersebut sebagai upaya menumbuhkan minat baca siswa karena kurangnya minat baca anak-anak sekarang. Upaya yang dilakukan sekolah melalui penyediaan fasilitas yang mendukung penerapan kegiatan Literasi dan kegiatan penunjang peserta didik dalam membaca (Hartati, 2020).

Berdasarkan paparan di atas, membaca merupakan suatu kegiatan yang mampu memperoleh banyak pengetahuan namun diketahui menurut beberapa data tentang literasi menyatakan rendahnya minat baca masyarakat Indonesia. Pemerintah Republik Indonesia melalui Kemendikbud telah merealisasikan Program Gerakan Literasi Sekolah (GLS) diterapkan di sekolah sebagai salah satu cara untuk menumbuhkan serta meningkatkan minat baca siswa. SDIT Qurrata A'yun adalah salah satu sekolah yang menerapkan Budaya Literasi sebagai upaya dalam menumbuhkan minat baca siswa. Oleh karena itu, peneliti sangat tertarik melakukan penelitian yang berjudul upaya menumbuhkan minat baca siswa melalui Budaya Literasi di SDIT Qurrata A'yun Kandangan. Penelitian ini memiliki kontribusi yakni diharapkan dapat dijadikan sebagai contoh bagi Sekolah Dasar lain yang menginginkan sekolahnya sebagai basis kegiatan Literasi.

\section{METODE}

Penelitian ini menggunakan metode pendekatan kualitatif jenis deskriptif untuk memperoleh gambaran mengenai upaya menumbuhkan minat baca siswa melalui budaya literasi di SDIT Qurrata A'yun Kandangan. Sumber data penelitian terdiri dari data primer dan data sekunder. Sumber dat a primer adalah 1) informasi yang diperoleh dari hasil wawancara dengan kepala sekolah, Waka Kurikulum Sekolah Waka Kesiswaan Sekolah, Kepala Perpustakaan, Koordinator Perpustakaan, Guru, Siswa, Orang tua siswa dan hasil pengamatan di lapangan terkait dengan fisik, dokumen, dan keadaan yang berkaitan dengan upaya menumbuhkan minat baca siswa melalui budaya literasi. Sedangkan data sekunder peneitian ini seperti buku terbitan, jurnal ilmiah, dan lain sebagainya. Instrumen yang digunakan dalam pengumpulan data adalah wawancara, observasi lapangan, dan dokumentasi. Analisis data peneliti melalui reduksi data, penyajian data dan penarikan kesimpulan yaitu menggunakan model Miles dan Huberman (Sugiyono, 2017). Teknik pemeriksaan keabsahan data dilakukan dengan trianggulasi sumber, trianggulasi Teknik dan trianggulasi waktu (Sugiyono, 2017).

\section{HASIL DAN PEMBAHASAN}

\section{Hasil}

SDIT Qurrata A'yun Kandangan menerapkan upaya menumbuhkan minat baca siswa melalui penerapan Budaya Literasi dalam kegiatan sehari-hari di sekolah maupun pada saat di rumah dimana pihak sekolah juga bekerjasama dengan orang tua dirumah. Dalam menumbuhkan minat baca siswa di SDIT Qurrata A'yun Kandangan ada beberapa upaya yang dilakukan sekolah melalui jaminan mutu sekolah Program Budaya Literasi diantaranya adalah:

1. Penyediaan Buku

Dalam penerapan Budaya Literasi di SDIT Qurrata A'yun dalam upaya menumbuhkan minat baca siswa sekolah berupaya menyediakan buku dan bahan bacaan di perpustakaan yang di kelola oleh tim perpustakaan. Dengan adanya buku dan bahan bacaan yang tersedia dapat membuat siswa senang mengunjungi 
perpustakaan dan gemar dalam membaca serta dapat menumbuhkan minat baca siswa di SDIT Qurrata A'yun Kandangan.

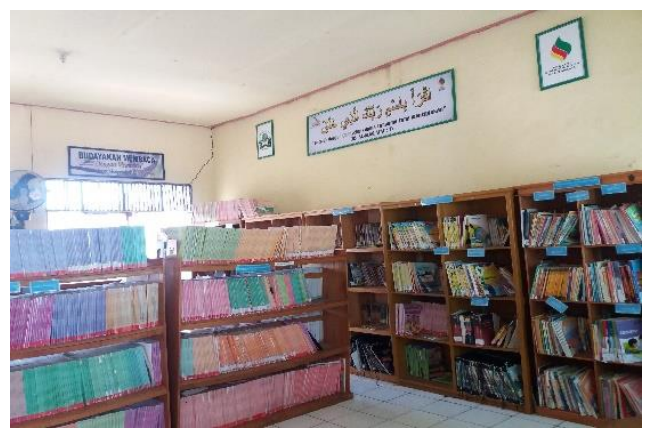

Gambar 1. Penyediaan Buku dan Bahan Bacaan

2. Jadwal Literasi

Pembagian jadwal kunjungan Literasi ke Perpustakaan SDIT Qurrata A'yun yang dikelola oleh tim perpustakaan bekerjasama dengan wali kelas untuk mengarahkan siswa mengunjungi perpustakaan dengan jadwal yang sudah dibagikan oleh tim perpustakaan. Kunjungan keperpustakaan dilakukan 1 minggu sekali setiap kelasnya untuk membaca buku selama 10-15 menit. Dengan adanya penerapan pembagian jadwal kunjungan iterasi ke perpustakaan tersebut setiap bulannya terdapat peningkatan dan dapat menumbuhkan minat baca siswa di SDIT Qurra A’yun Kandangan.

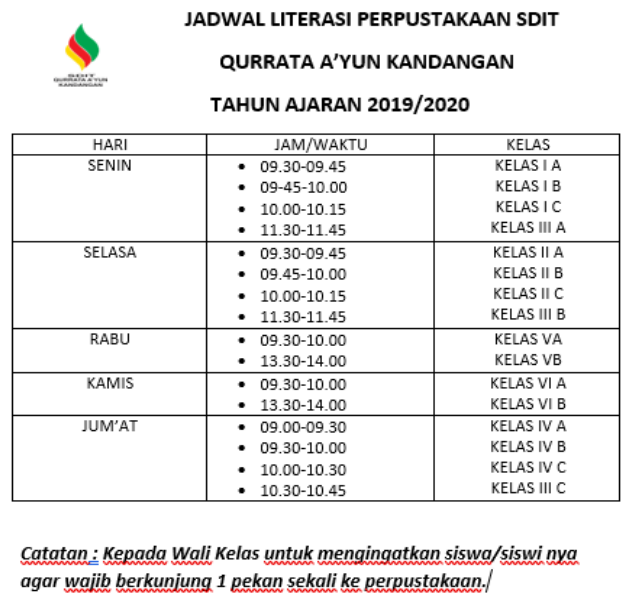

Gambar 2. Jadwal kunjungan Literasi

3. Membuat Mading (Majalah dinding)

Kegiatan pembagian membuat mading yang dikelola oleh tim perpustakaan SDIT Qurrata A'yun Kandangan dilakukan secara bergantian setiap kelasnya. Dengan adanya kegiatan membuat mading setiap kelas dapat mencari isi mading melalui buku dan bahan bacaan lainnya sehingga menumbuhkan minat baca siswa melalui pembuatan mading tersebut. 


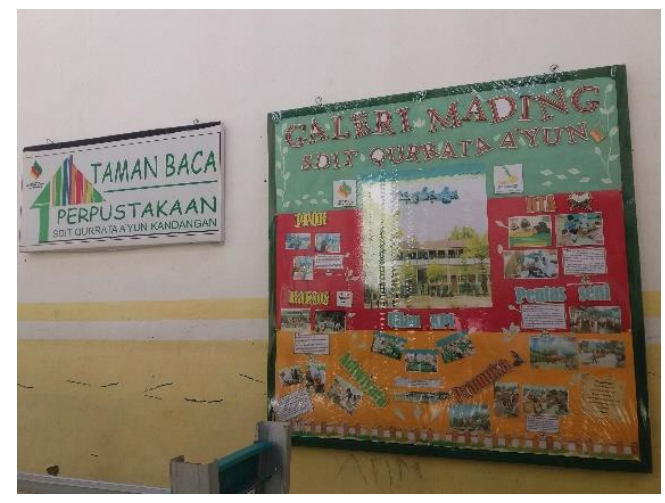

\section{Reward}

Gambar 3. Mading (Majalah Dinding)

SDIT Qurrata A'yun Kandangan menerapkan pembagian reward bagi kelas yang sering berkunjung ke perpustakaan dan reward untuk siswa yang gemar membaca sehingga menjadikan motivasi siswa semangat dalam membaca buku dan dapat menumbuhkan minat baca semua siswa di SDIT Qurrata A'yun Kandangan.

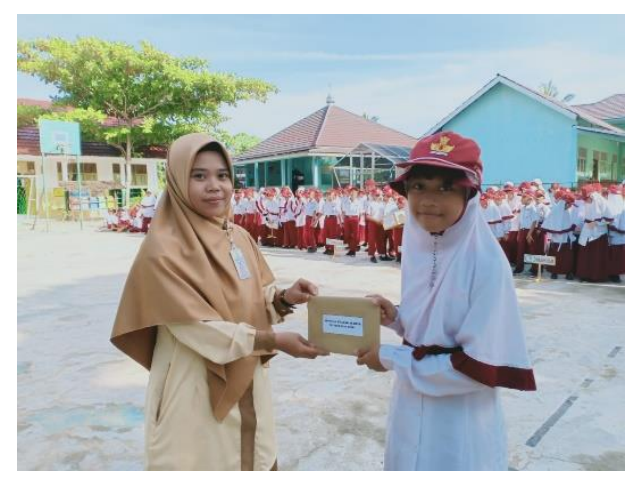

Gambar 4. Pemberian Reward

5. Pojok Baca

Penyediaan pojok baca disetiap kelas SDIT Qurrata A'yun digunakan untuk penerapan kegiatan literasi pada saat di dalam kelas. Sebelum memulai pelajaran atau pada saat jam kosong siswa membaca buku di pojok baca kelas. Dengan adanya penyediaan pojok baca tersebut sehingga dapat meningkatkan dan menumbuhkan minat baca semua siswa di SDIT Qurrata A'yun Kandangan.

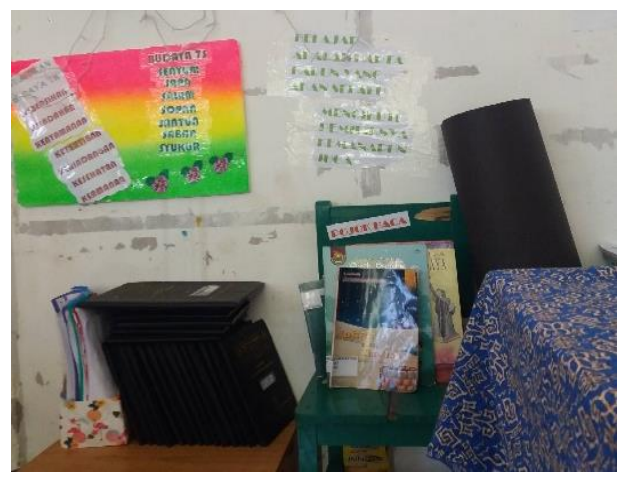

Gambar 5. Pojok Baca 
6. Perpustakaan Keliling

Budaya Literasi SDIT Qurrata A'yun Kandangan juga bekerjasama dengan program literasi dari dinas Pendidikan melalui Perpustakaan Daerah melakukan kunjungan perpustakaan keliling. Dengan adanya perpustakaan keliling tersebut siswa terlihat antusias membaca buku sehingga dapat meningkatkan dan menumbuhkan minta baca siswa di SDIT Qurrta A'yun Kandangan.

Dalam penerapan budaya literasi juga terdapat beberapa pihak yang saling berkerjasama yakni Yayasan, tim manajemen sekolah, kepala sekolah, waka kurikulum sekolah, waka kesiswaan sekolah, pustakawaan, guru, siswa, orang tua dan tentunya Dinas Pendidikan dan Instansi yang terkait dengan Literasi. Hal tersebut membuktikan bahwa semua pihak memiliki andil dalam upaya menumbuhkan minat baca siswa yang tidak hanya dibebankan pada pihak sekolah.

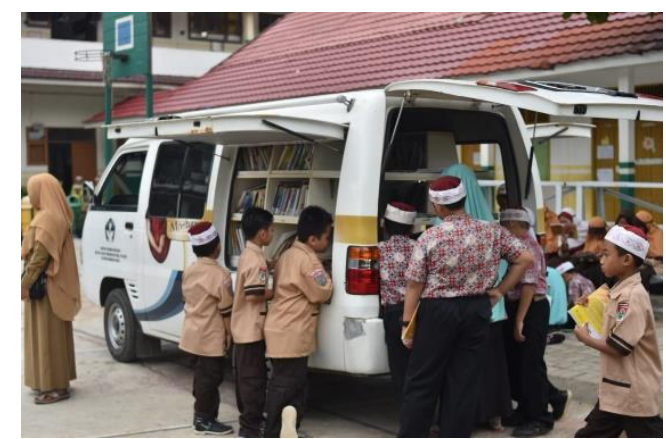

Gambar 6. Perpustakaan Keliling

\section{Pembahasan}

Dalam menumbuhkan minat baca siswa di SDIT Qurrata A'yun Kandangan ada beberapa upaya yang dilakukan sekolah melalui jaminan mutu sekolah Program Budaya Literasi diantaranya adalah:

1. Penyediaan Buku

Upaya untuk mengkondisikan tersedianya materi bacaan yang sesuai dengan tingkatan perkembangan peserta didik yang dapat memperkuat minat baca anak (Satrio Imanugroho dan Roro Isyawati, 2019). Tersedianya berbagai macam pilihan dan bacaan dalam kegiatan membaca dapat menigkatkan motivasi membaca (Guthrie \& Homenick, 2013). kemudahan dalam mengakses buku di perpustakaan merupakan salah satu faktor kunci dalam mengembangkan kebiasaan membaca (Rodirgo 2014). Keberhasilan kegiatan literasi di sekolah perlu diupayakan melalui peningkatan jumlah dan ragam sumber bacaan bermutu dan kegiatan perluasan akses sumber belajar dan cakupan peserta belajar penyediaan pojok baca, yang ada di setiap kelas maupun di tempat strategis di sekolah (Kemendikbud, 2019).

2. Jadwal Literasi

Suherman yang menyatakan perpustakaan mempunyai peranan yang signifikan untuk mendukung aktivitas gemar membaca dan meningkatkan kegiatan literasi, juga mengembangkan siswa supaya dapat belajar secara independent (Suherman, 2009). Berhasilnya penerapan kegiatan literasi di sekolah perlu mengupayakan kegiatan-kegiatan yang menumbuhkan budaya 
literasi, salah satunya adalah penguatan tata kelola melalui pengalokasian jadwal khusus untuk berbagai kegiatan literasi di sekolah (Kemendikbud, 2019). Program perpustakaan yang ada di sekolah meliputi berbagai aktifitas yang mendukung kurikulum sekolah dan berkontribusi untuk pengembangan kegiatan belajar di masa akan datang. Oleh karena itu, perpustakaan memiliki tugas dalam mendukung kegiatan proses belajar mengajar tersebut dengan, 1) mengembangkan, mengolah, meminjamkan buku dan bahan Pustaka lainnya, baik yang tercetak maupun non cetak. 2) Memberi pelayanan kebutuhan bahan pelajaran yang diperlukan saat proses belajar mengajar di dalam maupun di luar kelas. 3) Menyediakan sumber-sumber informasi bagi seluruh civitas akademik di sekolah. 4) Menyiapkan jam kunjung perpustakaan sesuai dengan kebijakandan kebutuhan waktu berkunjung perpustakaan sesuai dengan kebijakan dan kebutuhan waktu berkunjung pemustaka di sekolah. 5) Mendidik siswa untuk dapat mencari informasi secara mandiri dan membudayakan keterampilan literasi informasi dan teknologi. 6) Melatih siswa agar dapat menggunakan buku atau literatur referensi di perpustakaan. 7) Mengadakan penelitian sederhana sesuai dengan tugas yang diberikan guru (Ade Nufus, 2018). strategi upaya yang dilakukan sekolah dalam meningkatkan minat membaca siswa yakni dengan beberapa kegiatan salah satunya dengan memantau pelaksanaan wajib kunjung perpustakaan (Ira Nur Maulidah, 2017). Undang-Undang No. 43 Tahun 2007 tentang Perpustakaan pasal 48 ayat (1) dan (3) yang berbunyi "Pembudayaan kegemaran membaca dilakukan melalui keluarga, satuan Pendidikan, dan masyarakat" dan "Pembudayaan kegemaran membaca pada satuan Pendidikan sebagaimana dimaksud pada satuan Pendidikan dengan membanggakan dan memanfaatkan perpustakaan sebagai proses pembelajaran (Satrio Iamanugroho dan Roro Isyawati, 2017).

3. Membuat Mading (Majalah dinding)

Mading atau Majalah dinding mempunyai manfaat, yaitu: (1) dapat meningkatkan minat baca, (2) pengembangan ilmu pengetahuan, (3) media pengajaran, (4) pengisi waktu luang dan penyalur serta penampung bakat, minat, dan hobi seseorang (5) dokumentasi dan (6) sumber informasi keilmuan (Widodo, 1992). Pembuatan majalah dinding mempunyai peran yang sangat penting bagi siswa dikarenakan dapat menjadi sumber informasi serta sarana literasi informai untuk menumbuhkan dan meningkatkan minat baca siswa (Nia Permata Sari, 2016).

4. Reward

Kegiatan pemberian reward ini juga mempunyai peran dalam meningkatkan minat baca masyarakat khususnya di Desa Sukomangli (Lutfatul Latifah Eka Putri, 2017).

5. Pojok Baca

Dalam penelitian yang dilakukan Moh Adib Rofi'iUddi di SMP Negri 3 Pati menunjukan hasil analisis statistic dengan rumus korelasi menggunakan SPSS 20 dengan hasil signifikansi hitung 0.000 lebih kecil dari 0.05 sehingga H0 ditolak artinya terdapat pengaruh signifikan antara variabel $X$ (pojok baca) dan variabel Y terjadinya peningkatan minat baca siswa dengan adanya tersedianya pojok baca di sekolah (Moh Adib Rofi'IUddin, 2017). 
6. Perpustakaan Keliling

Pendidikan seharusnya melibatkan komponen masyarakat yaitu, keluarga, pendidik professional, pemerintah, dll dalam membina, memberi contoh atau memberi inspirasi, memberi motivasi semangat, dan mendorong perkembangan anak (Ranti Wulandari, 2017). Jalur Pendidikan terdiri dari pendidikan formal, nonformal, dan informal yang dapat saling melengkapi. Pendidikan formal menurut pasal 14 "terdiri atas pendidikan dasar, pendidikan menengah, dan Pendidikan tinggi." Pendidikan nonformal menurut pasal 26 ayat 4 "terdiri atas lembaga pelatihan, lembaga kursus, kelompok belajar, pusat kegiatan belajar masyarakat, dan majelis taklim, serta satuan pendidikan yang sejenis." Pendidikan informal menurut pasal 27 ayat 1 adalah pendidikan "yang dilakukan oleh keluarga dan lingkungan yang berbentuk kegiatan belajar secara mandiri." (UUD RI pasal 13 ayat 1). peran perpustakaan keliling menyediakan berbagai macam-macam koleksi mulai dari budidaya, pertanian, dan juga peternakan. Sumber informasi yang telah disediakan telah membantu kebutuhan masyarakat, dengan disediakan koleksi bahan bacaan tersebut tidak hanya menumbuhkan dan meningkatkan minat baca saja, namun juga dapat terlihat dampaknya yaitu masyarakat memiliki bebagai variasi dalam hasil pertanian mereka (Riskha Arumsari, 2017).

\section{PENUTUP}

Berdasarakan hasil penelitian yang telah dilaksanakan terkait upaya menumbuhkan minat baca siswa melalui budaya literasi di SDIT Qurrata A'yun Kandangan, maka dapat ditarik kesimpulan sebagai berikut:

1. Penyediaan Buku

2. Jadwal Literasi

3. Membuat Mading

4. Pemberian Reward

5. Pojok Baca

6. Perpustakaan keliling

\section{UCAPAN TERIMA KASIH}

Penulis mengucapkan terima kasih kepada Program Studi Pendidikan Guru Madrasah Ibtidaiyah (PGMI) Fakultas Studi Islam Universitas Islam Kalimantan Muhammad Arsyad Al Banjari Banjarmasin yang telah mendukung dalam pelaksanaan penelitian ini.

\section{DAFTAR PUSTAKA}

Al Baihaqi, Abu Fathan Al Baihaqi (2013), Mushaf Khadijah, Jakarta: CV AlFatih Berkah Cipta.

Andi Prastowo, (2013). Manajemen Perpustakaan Sekolah Profesional, Jogjakarta: Diva Press.

Arumsari, Riskha. (2017). Peran Perpustakaan Keliling dalam Menumbuhkan Minat Baca Masyarakat Desa Kepek Kecamatan Saptosari Kabupaten Gunungkidul, Skripsi pada Universitas Diponegoro.

Astriati, Puspo. (2016). Minat Baca di Perpustakaan SD Negri Glagah Yogyakarta, Skripsi pada Universitas Islam Negri Sunan Kalijaga.

Dalman, (2013). Keterampilan Membaca, Jakarta: Raja Grafindo Persada. 
Daroini, Ahmad Islahud. (2018). Tafsir Ayat Pendidikan Dalam Q.S Al-'Alaq Ayat 1-5 Menurut Quraish Shihab, Skripsi pada Universitas Islam Negri Raden Intan Lampung.

Rahim, Farida. (2008). Pengajaran Membaca di Sekolah Dasar, Jakarta:Bumi Aksara.

Galuh Ayu Puspita, Irwansyah, Pergeseran Budaya Baca dan Perkembangan Industri Penerbitan Buku di Indonesia, Jurnal Bibliotika, 2 (1), 13.

Hamdani, (2019, November 6). laporan “World's Most Literate Nations”, Indonesia Darurat Literasi Membaca, dikutip dari kompasiana: https://www.google.com/ kompasiana.com.

Hartono. (2016). Manajemen Perpustakaan Sekolah. Yogyakarta: Ar-Ruzz Media.

Ibn Katsir Al-Dimisqi, Abu Fida Al-Hafiz. (2002). Tafsir Al-Qur'an Al- 'Adzim, Jilid 4, Beirut:Dar Al-Fikr.

Imamnugroho. Satrio. Dan Isywati, Roro. (2019). Program Gerakan Literasi Sekolah Dalam Menumbuhkan Minat Baca Peserta Didik SDN Kuripan LOR 01 Kota Pekalongan, 2.

Imran dkk, Budaya Literasi Melalui Program GLS Dalam Menumbuhkan Minat Baca Siswa SD Negri Melayu, Jurnal Penelitian dan Penalaran, 4 (1), hlm. 702.

Islahud Daroini, Ahmad. (2018). Tafsir Ayat Pendidikan Dalam Q.S Al-'Alaq Ayat 1-5 Menurut Quraish Shihab, Skripsi Universitas Islam Negri Raden Intan Lampung.

Kemendikbud. (2016). Buku Saku Gerakan Literasi Sekolah, Jakarta: Kemendikbud.

Kemendikbud. (2017). Panduan Gerakan Literasi Nasional. Jakarta: Kementrian Pendidikan dan Kebudayaan.

Kemendikbud. (2019). Panduan Gerakan Literasi Nasional, Jakarta: Kementrian Pendidikan dan Kebudayaan.

Kholianti, (2011). Hubungan Antara Frekuensi Kunjung Sekolah dengan Minat Baca Siswa Kelas IV di SDN 3 Sentulo.gan, Skripsi: PGSD Universitas Negri Yogyakarta.

Khotimah, Khusnul dkk. (2019). Pelaksanaan Gerakan Lierasi Sekolah, Jurnal Pendidikan, 3 (11), 1448-1498.

Laksono, Kisyani. dkk. (2016). Manual Pendukung Gerakan Literasi Sekolah, Jakarta: Kementrian Pendidikan dan Kebudayaan.

Latifah Eka Putri, Lutfatul. (2017). Pengaruh Pemberian Reward Pada Pola Pembinaan Minat Baca Pemakai di Taman Baca Masyarakat Lentera Hati Desa Sukomangli Kecamatan Reban Kabupaten Batang, Skripsi pada Universitas Diponegoro.

Ma'mur, Lizamudin. (2010). Membangun Budaya Literasi: Meratus Komunitas Global, Jakarta: Diadit Media.

Ma'mur, Lizamudin. (2010). Membangun Budaya Literasi: Meratus Komunitas Global, Jakarta: Diadit Media.

Maulidah, Ira Nur. (2017). Upaya Stategi Peningkatan Minat Membaca Siswa Kelas 1B Tema 8 Subtema 2 Bahasa Indonesia SDN Krebet Bululawang Malang, Skripsi pada Universitas Islam Negri Maulana Malik Ibrahim Malang.

Mitasari, Lea Sakti, (2018), Peran Kegiatan Literasi dalam Meningkatkan Minat Membaca dan Menulis dan Menulis Siswa Kelas Atas di SDN Gumpang 1, Skripsi Universitas Muhammadiyah Surakarta

Mustolehudin. (2011), Tradisi Baca Tulis dala Islam Kajian Terhadap Teksi Al-Qur'an Surah Al-"Alaq Ayat 1-5. Jurnal "Analisa, 148-149. 
Musfiroh, T., \& Listyorini, B. (2016). Konstuk Kompetensi Literasi Untuk Siswa Sekolah Dasar, Jurnal Literasi, 15 (1).

Nufuz, Ade. (2018). Gerakan Literasi dan Dampaknya Terhadap Pengembangan Perpustakaan Sekolah Luar Biasa Negri 1 Yogyakarta, Tesis pada Universitas Islam Kalijaga, Yogyakarta.

Oktaviani, Anisa. (2019, Oktober 07). Pemberian Reward kepada siswa yang sering membaca dan meminjam buku di perpustakaan sekolah. (Shinta Interviewer).

Perpustakan Nasional. (2012). Standar Nasional Perpustakaan, Jakarta: Perpustakaan Nasional.

Prastowo, Andi. (2012). Manajemen Perpustakaan Sekolah Profesional. Jogjakarta: DIVA Press.

Prastowo, Andi. (2016). Metode Penelitian Kualitatif dalam Perspektif Rancangan Penelitian. Jogjakarta: Ar-Ruzz Media.

Puspita, Galuh Ayu, Irwansyah. (2018). Pergeseran Budaya Baca dan Perkembangan Industri Penerbitan Buku di Indonesia, Jurnal Bibliotika, 2 (1), 13.

Rahim, Farida. (2008). Pengajaran Membaca di Sekolah Dasar, Jakarta: Bumi Aksara.

Rodrigo, Victoria dkk. (2014). Changes in Reading Habits by Low Literate Adults though Extensive Reading, Reading in Foreign Language, 26 (1), 73-91.

Rofi uddin, Moh Adib. (2017). Pengaruh Pojok Baca Terhadap Peningkatan Minat Baca Siswa di SMP Negeri 3 Pati, Skripsi pada Universitas Diponegoro.

Sari, Nia Permata. (2016). Mading Sebagai Sarana Literasi Informasi Untuk Meningkatkan Minat Baca Siswa di Perpustakaan SDN Percobaan 3 Pakem, Skripsi pada Universitas Islam Negeri Sunan Kalijaga Yogjakarta.

Sholihin, Lukman. dkk. (2019). Indeks Aktvitas Literasi Membaca 34 Provinsi, Jakarta: Pusat Penelitian Kebijakan Pendidikan dan Kebudayaan, Badan Penelitian dan Pengembangan, Kementrian Pendidikan dan Kebudayaan.

Sugiyono, (2014), Metode Penelitian Pendidikan, Bandung: Alfabeta.

Sugiyono. (2017). Metode Penelitian Kualitatif. Bandung: Alfabeta

Suherman. (2009). Perpustakaan Sebagai Jantung Sekolah, Bandung: MQS Publishing.

Safilla, Yanita. (2014). Peran Perpustakaan SD An-Nisaa' Dalam Meningkatkan Literasi Informasi, Skripsi pada Universitas Islam Negri Syarif Hidayatullah Jakarta.

Wulandari, Ranti. (2017). Implementasi Kebijakan Gerakan Literasi Sekolah di Sekolah Dasar Islam Terpadu Lukman Al Hakim Internasional, Jurnal Kebijakan Pendidikan, Nomor 3 (VI), 321. 